\title{
Política social, paradigma de bien estar y práctica política
}

David Martínez *

Aloisio Ruscheinsky ${ }^{* *}$

\section{Resumen}

El artículo aborda la realidad de las desigualdades y las políticas sociales orientadas a la creación de mecanismos de bienestar social. Estos procesos figuran como las tentativas de la superación de la pobre$z a$, se traducen en retos históricos situados en un contexto espacial de los conflictos entre los actores sociales. En este sentido, parecía a nosotros apropiado construir una exposición de algunos suportes teóricos de apoyo a la interpretación que venían a amparar un análisis de las políticas sociales en el contexto del pluralismo de bienestar en América Latina.

Palabras clave: desigualdades, política social, bienestar, América Latina, actores sociales.

Dr. en estudios científico-sociales, académico de la Universidad Iberoamericana León. Sus temas de investigación se relacionan con pobreza, política social y gobiernos locales. Email da-

vid.martinez@leon.uia.mx

Dr. en sociología, docente de posgrado en la Universidad Unisinos, São Leopoldo, Brasil, tiene interese en investigaciones en las tematizaciones de las desigualdades, actores sociales y medio ambiente. Email aloisior@unisinos.br

\section{Introducción}

Considerando los cambios recurrentes en un breve período histórico, el articulo intenta esbozar el tiempo y el espacio de los enfoques, para computar los avances y retrocesos o evitar malos entendidos: a) tuvo un trágico período de gobiernos autoritarios, con una dura represión

y la sociedad civil diferenciada o la retirada de la esfera pública, mientras un proceso de modernización conservadora, b) un reciente proceso de (re)democratización, nueva normativa constitucional y las manifestaciones de un ordenamiento por los nuevos derechos, pero ha logrado profundos reveses impuestos por la lógica neoliberal, c ) frente a las peculiaridades nacionales no hay que entender las mismas en cuanto sociedades habitualmente uniformes, como si en las políticas sociales si se tratara como a un consenso, porque son una expresión permanente de la gestión de conflictos, d) en medio de cambios en curso está el caso de la reconfiguración de los oligarcas o de los gobiernos populistas sucesivos y su aversión o adhesión a las políticas sociales universales, así como las influencias de la perspectiva neoliberal en su formulación y ejecución.

En tal sentido un estudio particular de la naturaleza de las desigualdades históricas, cuya perspectiva desde nuestro punto de vista, es imperativa para tratar de entender por qué la política pública y concretamente la política social tiene impactos diferenciales en un país. Aquí es, desde nuestra perspectiva, en donde se genera el 
puente para hablar de prácticas políticas similares para combatir la pobreza. Sin lugar a dudas, as heterogeneidades nos llevan a hablar de las privaciones o de riesgos de una parte de la población, pero entendemos a éstas en el marco de las diferencias y de los ejes que las producen dentro de un país. Las políticas sociales pretenden dar respuestas desde una perspectiva política a los problemas sociales en particular; pero la interrogación que se plantea o se queda a responder si las políticas sociales han implementado un juego de distribución que están cambiando las bases históricamente arraigadas de las desigualdades sociales.

El texto que ahora se ofrece para su discusión tiene el propósito de presentar a los investigadores algunas notas sobre ejes ordenadores de la discusión conceptual, que permitirá lograr un doble propósito*: 1) compartir, discutir y sobre todo construir visiones, conceptos y enfoques homologables sobre el problema de la política social ante la persistente pobreza continental; 2) recortar y enfocar el objeto de investigación desde las opciones teórico/metodológicas combatibiles con la realidad latinoamericana.

En efecto, un protocolo de investigación no se diseña de una vez y para siempre sino que se va modificando en la medida que el problema se confronta con la teoría y esto a su vez sirve para enriquecer, recortar y precisar los alcances de la propia investigación. La fortaleza de los

\footnotetext{
* Este texto es parte del marco conceptual y del diseño metodológico de una propuesta de investigación, bajo la denominación Proyecto Observatorio del AUSJAL, sobre pobreza, desigualdades y políticas sociales en América Latina, que en las líneas generales del trabajo de investigación debe sustentar un diagnóstico de las políticas y prácticas nacionales, son participantes los países de Venezuela, Colombia, México, Brasil, República Dominicana, Ecuador, Chile y Uruguay, Argentina.
}

paradigmas de lo bienestar radica en la importancia que tienen las ideas y la argumentación para los cambios sociales, en circunstancias de profundos conflictos históricos y sociopolíticos. Hay que mirar por las circunstancias en que las variables estructurales presionan para que haya cambios pero no ofrecen explicaciones sobre la naturaleza y las razones latentes del cambio. Este sólo se significa a partir del repertorio de alternativas que poseen los tomadores de decisiones y las posturas de los actores sociales.

El método de investigación fundamentalmente basado en las ciencias sociales para comprender la sociedad desigual tiene en cuenta, en general, las dimensiones políticas de la vida cotidiana y las determinaciones estructurales. Estas dimensiones no asumen acciones lineales, rompiendo con la división exacta de los espacios públicos y privados, pero tenían en cuenta el regresivo-progresivo en las encuestas y en la realidad histórica, sobre todo por que la historia y las prácticas políticas no siempre evolucionan a mejor para el ser humano. La perspectiva de los modelos y consecuencias de las políticas sociales es discutida abordando el contexto de las políticas sociales con el objetivo del bienestar social.

El problema social que origina el interés por la investigación es la existencia de una incapacidad crónica para atender las demandas básicas de inmensas franjas de la población. Las inquietudes académicas que confluyen en este texto constituien interrogantes suscitadas sobre el debate alcanzado con respecto a la conceptualización, diseño, operación, evaluación y comparación de las prácticas en las políticas sociales. 
Consideramos que el análisis y la comparación de la trayectoria de la política social si se hace desde una mirada construida con conceptos que por su novedad y potencia han venido tomando forma a lo largo de las últimas décadas, pueden aportar elementos para el replanteamiento del papel de las distintas esferas productoras de bienestar y en ese sentido aportar algunas propuestas dirigidas a los gestores públicos y grupos de influencia en Latinoamérica para reenfocar las políticas sociales hasta ahora aplicadas.

Para convertir el problema social expuesto en este panorama de las desigualdades a un problema de investigación, resulta crucial contar con un aparato conceptual sólido que permita aportar un punto de vista novedoso al debate que universidades, centros de investigación y agencias internacionales vienen impulsando. Pensamos que es pertinente indagar sobre los paradigmas de bienestar sustentantes, los regímenes de bienestar que operan en la realidad, el proceso de institucionalización con que se intenciona la producción de bienestar y las estrategias programáticas que se han aplicado en los diferentes países de forma que se profundice la relación entre el bienestar de la población, la pobreza y la responsabilidad pública frente a la estructura de los riesgos sociales que cada país ha producido.

\section{Ejes de las prácticas en la políti-} ca social: paradigma y régimen.

Existe una extensa y compleja discusión sobre las escuelas de pensamiento que se encuentran en la base de los estudios de la política social y la pobreza, no sólo en América Latina. En la elecciónconstrucción de un posicionamiento se leva en consideración que la política social es un campo de conflicto, donde compiten opciones ideológicas y enfoques teóricos.

Para la investigación que nos proponemos impulsar, se evita de entrada la elección de alguna corriente que tenga un calificativo elaborado de antemano (crítica, instrumental, social demócrata, conservadora o administrativa, entre otras) y a partir de ella derivar las tesis fundamentales de la articulación. En lugar de ello se proponen tres ejes de discusión que caractericen los puntos álgidos del debate y en una construcción que tendrá abrir el espacio para señalar acuerdos, desacuerdos y ajustes.

Una elección que se debe explicitar y que proviene de cierto rigor metodológico es que nuestro objeto de investigación tiene en su núcleo central a la política social, en cuyo prospecto vamos a tratar de correlacionar las formas de protección o bienestar social y los caminos de la ciudadanía en consonancia con da literatura sobre el fenómeno en curso en los países de Latinoamérica (Draibe y Riesco, 2006). En efecto, nos interesa traer elementos para referir a las distintas experiencias de política social y desde ahí observar su relación con el combate a la pobreza. Por tanto la pobreza tendría el carácter de variable dependiente en el caso de que siguiéramos una investigación hipotética deductiva, o para ser más claros en una visión constructivista, las preguntas de investigación pondrán énfasis en la política social como núcleo central articulador.

Por tanto proponemos tres ejes organizadores para la discusión inicial: la política social y el bienestar (paradigma y régimen) en la historia contemporánea; la política social en su relación con el abatimiento de la desigualdad y la pobreza; la política social en el marco de la construcción de la ciudadanía. El primer eje es con- 
siderado como el central pues contiene definiciones de fondo que serán profundizados en los dos ejes restantes. Vale la pena subrayar que sólo son ordenadores de la discusión, es decir, elementos aglutinadores y puertas de entrada que dan pié al tratamiento de otros conceptos.

Del conjunto de aproximaciones teóricas tomaremos a Gosta EspingAndersen (2000; 2007; 2009), tanbien los aportes realizados por Barba (2007) y Filgueira et al (2006), así como los apuntes de José Adelantado (2000; 2005). Aunque estos autores tienen diferencias en el tratamiento de este primer eje de comprensión de las políticas de combate a la pobreza, en el desarrollo de este apartado se encontrarán aspectos comunes y complementarios en sus reflexiones, muy útiles en la comprensión del concepto de política social ubicado en una discusión más amplia del régimen de bienestar. Una primera perspectiva general en la que los autores coinciden sería la siguiente:

1) La necesidad de impulsar una reflexión crítica sobre el papel del mercado en el problema del bienestar. Los autores coinciden en la imposibilidad de encontrar o suponer un mercado perfecto o de subordinar las decisiones sociales a un criterio mercantilizante, pero también se reconoce la imposibilidad de hablar del bienestar social sin incorporar esta dimensión.

2) La impertinencia de que la política social pueda estar direccionada exclusivamente al combate de la pobreza. Sus objetivos profundos se encuentran en otras esferas: el logro de la restitución del tejido social, la disminución de la desigualdad, el aumento de capacidades de la población y la búsqueda de bienestar.

3) La existencia de esferas que son responsables del bienestar social: mercado, familia, estado y sociedad civil. Esta últi- ma es introducida, con fuerza, por Adelantado.

4) Los riesgos (objeto de la política social) de clase están asociados a los problemas de pobreza, y la atención a los sectores excluidos tiene su fundamento en un enfoque basado en derechos ciudadanos y no en la concesión asistencial y voluntarista de los gobiernos.

5) Las formas de enfrentar los riegos sociales son propios de cada país y no existen formas simples de importar o exportar esquemas sociales que no estén enraizados en la propia historia local.

6) La aceptación de las "nuevas" dinámicas que se generan en los últimos años, tales como el enfoque de género y los problemas medioambientales, como elementos constitutivos de una buena política social.

7) La política social no es un costo enviado a un fondo perdido, sino que colabora activamente en la dinamización económica de una sociedad.

Estos atontamientos introducen la necesidad búsqueda de algunas de las directrices teóricas de de referencia, particularmente las relacionadas con los regímenes de bienestar, el universalismo básico, las fuentes del bienestar, el familiarismo y la mercantilización y la relación de la política social con el bienestar (Franzoni, 2007; Zimmermann, 2009). De diversos modos se ha tratado de definir el concepto de bienestar, ya sea como un estado al que se llega a través de la posesión de ciertos bienes sociales, como una mera resultante subjetiva de grupos y personas o incluso anteponiendo al bienestar el bien-ser, para connotar una dimensión espiritual trascendente del ser humano que no se agota en los logros materiales.

Al modo de cómo Amartya Sen conceptualiza el desarrollo humano, se en- 
tenderá el bienestar como una capacidad, pero no como un estado de factor consumado. A capacidad sirve especialmente para el manejo de la incertidumbre en la contemporaneidad que se historiza de formas distintas (Franzoni, 2008): la enfermedad, la vejez, la discapacidad, el ambiente, el extranjero, la discriminación, el desempleo, la etnia, el divorcio, la muerte. Todas estas, entre otras, son situaciones que están sujetas a la incertidumbre vital, es decir, son ejemplos de riesgos de múltiples órdenes en una sociedad desigual y inicua.

Si se afirma que el bienestar es una capacidad para el manejo de los riesgos sociales, se sigue que en contextos latinoamericanos tal capacidad como otros procesos y bienes sociales está distribuida inequitativamente entre la población como producto de las inserciones distintas en la estructura social. En este efecto, los riesgos se presentan menos como producto de la mayor o menor capacidad de los individuos sino pero son consecuencia de arreglos sociales específicos que dan lugar a desigualdades y dominaciones étnicas, políticas, económicas y de género, entre otras. Para aprehender estas desigualdades es necesario contar con un nivel intermedio de análisis, que permita ubicar las desigualdades y inequidades, la dominación y opresión en los contextos específicos.

El concepto de régimen de bienestar se refiere a la "manera combinada e interdependiente como el bienestar es producido y asignado por el Estado, el mercado y la familia" (Esping-Andersen, 2000:34), es decir el efecto de las esferas dichas en las condiciones sociales de la población. La particular forma de articularse de esta tríada produce regímenes de bienestar diferentes. En el nivel macro, la producción de bienestar de cualquiera de los tres se halla relacionada con lo que ocurre con los otros dos. Y en el nivel micro, el bienestar de los individuos depende de cómo logren agrupar los inputs procedentes de los tres.

\section{Las interrogaciones a los regí-} menes del bienestar y la disección de las desigualdades históricas

Desde este apartado hasta el de crecimiento y bienestar social, se retoman las ideas del autor reconocido en el ámbito de la discusión sobre regímenes de bienestar, Gosta Esping-Andersen, quien considera que los diferentes estados nacionales se adhieren a una noción de igualdad distinta. Algunos hacen énfasis en la igualdad individual basada en cuotas: lo que uno paga es lo que uno recibe. Otros buscan la igualdad con programas universales, pero también varía lo que se ha de igualar ${ }^{\dagger}$ para proveer a los ciudadanos algo de la demanda por la justicia social.

Existe en la propuesta de EspingAndersen una pregunta central que una vez contestada nos refiere a los tres mundos distintos del capitalismo de bienestar y determina los diversos modelos de regímenes de bienestar y de política social: los modos en que se reparte la producción de bienestar entre el mercado, el estado y la familia. El autor construyó tres tipologías distintas ${ }^{\ddagger}$ : el régimen liberal, el conservador y el social demócrata. También considera que la mezcla privado-público constituía el

\footnotetext{
$†$ Por ejemplo, los escandinavos se han propuesto nivelar el capital social y los anglosajones escogen los grupos en desventaja para promover su movilidad.

¥ La tipología se vuelve estática en tanto representa condiciones que prevalecieron entonces (los años setenta y ochenta): una economía dominada por la producción industrial masiva, una estructura de clases en la que el trabajador manual masculino era el ciudadano prototípico y una sociedad en la que la familia era de tipo estable y con una sola fuente de ingresos.
} 
principal eje analítico que sustentaba una primera tipología de los tres mundos. Las dimensiones definitorias eran el grado de desmercantilización y los modos de estratificación, o si se quiere, las solidaridades. Las etiquetas que representan esta tríada explorados anteriormente también por $\mathrm{Ri}$ chard R. Titmuss y se derivan de la economía política europea. Aún así, es pertinente presentar las características de los tres regímenes de bienestar propuestos por Esping-Andersen, ya que representan la base de análisis que retoman distintos autores y de algún modo contiene los aspectos generales de las distintas políticas sociales en buena parte del mundo, por supuesto en Latinoamérica.

3.1. El régimen de bienestar conservador: posibles fuentes inspiración

Lejos de ser una expresión peyorativa, tipificar así a los estados de bienestar de Europa intenta señalar el impulso político detrás de su arquitectura. El régimen conservador se distingue por: 1) Su mezcla de segmentación de estatus y familiarismo, es decir, poco tiene que ver con el igualitarismo y se caracteriza por el corporativismo. Las primeras políticas sociales se inspiraron en el estatismo monárquico, en el corporativismo tradicional o en la Rerum Novarum. 2) Su característica particular es la inequidad en el reparto de riesgos, pues como régimen conservador tiene un legado estatista donde los funcionarios públicos son altamente beneficiados. 3) Un tercer atributo es el familiarismo, que es la combinación de la protección social sesgada a favor del varón, cabeza de familia, y el carácter central de la familia como dispensadora de cuidados y, en última instancia, responsable del bienestar de sus miembros. Lo que une a algunos países es el mantenimiento de la prescripción legal de que los padres (o los hijos) son responsables de sus hijos (o de sus padres) en caso de necesidad.

\subsection{El régimen de bienestar libe-} ral: concesiones necesarias.

Las raíces de la política social liberal se remontan a la economía política británica del siglo XIX, concretamente a sus nociones de menor elegibilidad y autosuficiencia, pero en lo más sua noción de economía alberga una fe ilimitada en el mercado. Los regímenes de bienestar actuales reflejan el compromiso político de minimizar al Estado, individualizar los riesgos y fomentar las soluciones del mercado. Por tanto, desfavorecen los derechos colectivos de la ciudadanía.

Considerando que hay variaciones, tres son las características del régimen liberal: 1) Es residual en el sentido que las garantías sociales se limitan a los malos riesgos o riesgos inaceptables. Adopta una definición restringida a la hora de elegir qué sujetos tienen derecho a dichas garantías. La política social liberal es, en gran medida, la del socorro a los niños pobres del siglo XIX, acreditados por la certificación de los bajos ingresos. El peso relativo de la asistencia social, basada en las necesidades en comparación con los programas de reconocimiento de derechos, debería constituir un excelente indicador del liberalismo. Los estados de bienestar anglosajones están orientados a favor de la asistencia social dirigida a sujetos específicos. 2) Abraza una concepción restringida acerca de qué riesgos se deben considerar sociales. Estados Unidos es un país extremadamente residual debido a su falta de asistencia sanitaria nacional, de subsidios de enfermedad, maternidad, familiares y de permisos laborales por paternidad. Para enfrentarse al fallo del mercado en estas áre- 
as, el planteamiento consiste en una ayuda orientada a los riesgos inaceptables. 3) El fomento al mercado en un planteamiento residual cultiva los dualismos: los sujetos de riesgos aceptables pueden valerse por sí mismos en el mercado; los de riesgos inaceptables pasan a ser dependientes de la asistencia social.

\subsection{El bienestar social demócrata:} las negociaciones al interior del Estado.

Este régimen es el prevaleciente en los países nórdicos. En Dinamarca, Noruega y Suecia, sus cimientos se construyeron entre las décadas de 1930 y 1940 con el advenimiento de un gobierno socialdemócrata estable. Finlandia tuvo que esperar veinte años más. Las raíces de la política social nórdica fueron liberales, después pasaron por políticas asistenciales y, posteriormente (1940-1960), llegaron a ser programas modernos de reconocimiento de derechos. Sin embargo, el embrión del universalismo estuvo presente desde el inicio en los programas escandinavos. Dinamarca se convirtió en un país pionero cuando, en 1981, la asistencia a la tercera edad se amplió a todo el colectivo de ancianos. Además, conforme Barba y Valencia (2000) este modelo contiene una cobertura de riesgos global, subsidios generosos, así como una idea clara de igualitarismo. Aquí, los derechos se vinculan a los individuos y se basan en la ciudadanía (mientras que las pensiones británicas y holandesas se basan en las aportaciones realizadas) antes que en una necesidad demostrada o en una relación laboral.

Lo que resulta especialmente socialdemócrata es, primero, la fusión del universalismo con la generosidad y segundo, su socialización global de los riesgos. El régimen socialdemócrata se distingue realmente por: 1) Su tentativa deliberada de marginar el papel de la asistencia basada en necesidades. 2) Su activo y explícito esfuerzo por desmercantilizar el bienestar y por minimizar o abolir su dependencia al mercado. Cerrar las puertas a los servicios de bienestar privados sólo resulta factible si los subsidios son suficientes. A su vez, conforme Manow (2007) hay algunas ventajas en la comparación institucional en el análisis de los regímenes de bienestar y es necesario tener en cuenta las nuevas coaliciones en la reforma o la lucha contra la reforma.

A los programas de subsidios en dinero, el régimen socialdemócrata lo complementa con una estructura de servicios enorme e integral dirigida a familias necesitadas. Este régimen articula el elemento igualitario, entendido como la práctica del universalismo donde toda la población disfruta de los mismos derechos y subsidios, sea rico o sea pobre, con la promoción activa del bienestar y las oportunidades vitales (en el caso de la mujer es patente) que implica la redistribución del ingreso y la eliminación de la pobreza. Aunque con ciertas crisis es claro el compromiso con el pleno empleo. El productivismo nórdico implica que el estado de bienestar debe garantizar que toda la población disponga de los recursos y la motivación necesarios para trabajar (y que el trabajo esté disponible). En cambio, el productivismo norteamericano (workfare) significa que se deben aceptar ciertos empleos a cambio de determinadas prestaciones sociales: se paga, se disfruta; no se paga no se disfruta. El régimen socialdemócrata implica un nexo dominado por el Estado, aunque actualmente pasan por una mala época. Las probabilidades de que encontremos el universalismo en el régimen socialdemócrata son elevadas y significativas. $\mathrm{Y}$ viceversa, las probabilidades de que 
encontremos servicios de bienestar privados son bajas, pero en lo que toca al régimen conservador, estas probabilidades son indistintas.

En términos comparativos EspingAndersen pondera el papel da familia, mercado, Estado, modo y lugar de la solidariedad predominante, grado de desmercantilización. Si el carácter residual del modelo liberal hace referencia al fallo del mercado, en el régimen conservador es una respuesta al fallo de la familia y esto determina a los sujetos a los que va dirigido. Por razones distintas, la política social liberal y conservadora tiene un enfoque pasivo de la gestión del empleo. La asistencia social no se concede a los adultos si sus padres pueden mantenerlos. Cuanto más familiarista es el Estado de bienestar menos generosos son los subsidios familiares. La provisión de subsidios a familias atípicas donde no es el varón el jefe (como madres solteras), suele ser marginal. El modelo liberal da prioridad a los mercados de trabajo no regulados. En el conservador, la gestión del empleo es una cuestión de apoyo familiar e inhibe que las mujeres casadas participen económicamente fuera del hogar.

\section{Politicas sociales: abatimiento de las desigualdades y las persistencias}

El segundo pivote de esta discusión teórica es el de la pobreza y como punto de partida que se irá enriqueciendo con las sucesivas discusiones, la entenderemos como un estado de privación de los bienes indispensables para la satisfacción de ciertas necesidades humanas, misma que lleva a la disminución de algunas capacidades de las personas y los grupos. Como el término de necesidades humanas abarca elementos de muy diversa naturaleza, como las afectivas, las relativas aso cuatro elementos de la naturaleza, las de participación, las de la cultura, las de reconocimiento y otras, se asume para este escrito que la pobreza estará caracterizada por la privación, hasta cierto nivel definido socialmente, de ingreso, de ciertos activos y de servicios públicos. Hay un largo debate sobre la definición de las necesidades humanas, desde Marx hasta nuestros días, que es por eso que hoy surge en la más mínima crítica o los beneficios sociales para la condición económica como si fuera la ciudadanía (Sposati, 2007; Pereira, 2006). La pobreza también se relaciona con la ausencia de medios, capacidades y recursos para modificar este estado de cosas y que socialmente ya se hacen posibles.

La posibilidad de obtener los medios indispensables para acceder a una vida digna es función de factores complejos y diversos como: la composición de la familia, la edad de los miembros (una familia formada por un par de ancianos requiere mayor cuidado en salud y menos en educación formal), el número de trabajadores activos, los servicios de que goza la comunidad donde se vive, la ubicación espacial del hogar, la cultura y las condiciones heredadas, la oferta y calidad del empleo y las condiciones de crecimiento y reparto de la riqueza de la nación, la capacidad de gestión y movilización política (Salama, 1999). Aunque aquí se enumeran los factores sin ponderación alguna, se debe subrayar que existe una jerarquía entre ellos, es decir, que no todos influyen del mismo modo para producir una situación de pobreza.

Se coincide con Boltvinik cuando señala que: "Si el concepto de pobreza ha de tener alguna utilidad, debemos restringirla a expresar la insatisfacción de aquellas necesidades humanas cuya satisfacción 
depende de condiciones económicas. De lo contrario, la pobreza se confunde con otras dimensiones del sufrimiento (o desventaja) del ser humano (...). Si incluyésemos como elementos constitutivos de la definición del concepto de pobreza esas necesidades cuya satisfacción no depende del acceso a los recursos, toda una población que vive en un régimen autoritario sería clasificada como pobre. Entonces, la capacidad diferenciadora del concepto (su habilidad para distinguir los pobres de los no pobres) se perdería y se volvería inútil como instrumento de política" (Boltvinik en Gallardo, 2001: 21).

Este punto es relevante porque no se niega la carencia de necesidades humanas en otros ámbitos de la vida humana tales como las psicológicas, las religiosas, las existenciales o las relativas a la participación democrática y que son constitutivas de cualquier persona. Todos somos seres incompletos, pero no todos somos seres humanos en estado de pobreza. Tampoco esta línea de pensamiento niega que la pobreza sea causa de un conjunto de redes sociales complejas que sobrepasan lo que en la economía suceda. Solamente enfoca el problema de una forma precisa y la diferencia de otras carencias humanas.

Las necesidades a las que hace referencia la definición anotada arriba tiene una clara connotación socioeconómica: son aquellas que tienen que ver con alimentación, salud, vivienda, ingreso, agua, corriente eléctrica, seguridad social, bienes del hogar (estufa, plancha, sillas, mesa, cama y otras) y educación. Con esta elección se renuncia a agrupar, bajo la categoría de pobreza, a toda carencia humana. Es frecuente que ante la preocupación por atender y entender la pobreza de índole socioeconómica existan críticas sobre la desatención de otras carencias individuales y grupales que, sin duda, representan también un obstáculo para la construcción de un mundo humano (Narbondo, 2006), tales como: la farmacodependencia, la soledad, la falta de sentido a la vida, la violencia directa y la desintegración familiar, entre otras.

Frente a las carencias no hay soluciones homegeneizantes. Es claro que no todas las personas necesitan lo mismo; incluso, hay variaciones entre las necesidades específicas propias de la pobreza rural mestiza, la pobreza indígena, la pobreza suburbana, pero lo que es evidente es que puede haber un acuerdo fundamental sobre los mínimos que una persona o una familia necesita para no vivir en condiciones de pobreza. Este acuerdo social afecta las bases de una sociedad democrática que dialoga y consensa para establecer un futuro común, lo mejor posible, así como las estrategias para avanzar hacia la equidad y el desarrollo. Las bases participativas en las soluciones de fondo incorporan, como actores principales, a los grupos empobrecidos y abre las puertas para relacionar pobreza, democracia y participación ciudadana (Morlino, 2005). La ciudadanía puede avanzar hasta a la acción de los ciudadanos con capacidad de controlar y evaluar las acciones del gobierno, cuyo camino de la corresponsabilidad ciudadana es vigilar su aplicación eficiente. Los afanes para erradicar la pobreza no significan que de ello dependa toda la felicidad ${ }^{\S}$ o el desarrollo humano, el bienestar en las invioladas dimensiones y la ciudadanía. Sin sombra

\footnotetext{
$\S$ Tampoco significa que el concepto de pobreza sea un megaordenador que indique la ausencia de todos los medios para acceder a una vida plena y feliz. Si hay un destino final de los esfuerzos para abatir la pobreza, ése, con toda seguridad, es el de justicia social, pero no necesariamente la felicidad o la vida plena en medio a la sociedad de libre concurrencia.
} 
de duda si hay un significado histórico y de orientación que ordene los esfuerzos para el derrocamiento de la pobreza pela acción de los movimientos sociales, con toda seguridad, es el utopia de implementar la justicia social.

Como apunta Calderón Gutiérrez (2002: 115), el tema de la justicia social es el telón de fondo de cualquier estrategia de desarrollo. La equidad, la inclusión social, el desarrollo humano y su contraparte, la desigualdad social, la polarización de dinero, del poder y de las oportunidades, son temas que le conciernen a una justicia social que, para que sea viable socialmente, debe contar con dos características: la critica ética y las condiciones para hacerla, realmente, deseada y posible.

\section{La pobreza de capacidades o capital social y democracia}

Es conveniente recalcar que aunque la pobreza se relaciona, fundamentalmente, con carencia de bienes de índole socio económico, no se agota ahí. En esta línea, durante la década de los noventa, aunque sus trabajos tienen una treintena de años de haberse iniciado, ha cobrado significación la línea teórica adoptada por Amartya Sen, en el sentido de entender a la pobreza como la privación de capacidades básicas, concepto que no se agota en la privación de bienes socialmente necesarios. Aproximarse a esta distinción enriquece las visiones, aumenta los argumentos para comprender la complejidad del fenómeno e introduce a la discusión sobre las libertades democráticas atrofiadas en la población empobrecida.

El desarrollo como el proceso de la ampliación de las capacidades e competencias (Sen, 1998; 2000) sirve para realizar actividades libremente elegidas y valora- das; la pobreza se ubica en esta línea de pensamiento como un obstáculo para el desarrollo humano, es decir, para poseer las capacidades fundamentales que permitan al individuo una construcción de la propia existencia, en niveles de vida, mínimamente aceptables.

El drama de esta situación de pobreza estriba en obstaculizar el que las personas con un nivel de ingresos insuficiente y con ciertas condiciones deficitarias de educación y de salud, puedan desarrollar determinadas funciones socialmente relevantes. El análisis de la pobreza debe estar enfocado en las posibilidades que tiene un individuo de funcionar, más que en los resultados que obtiene de ese funcionamiento, una vez que la escasez material es insuficiente para explicar el surgimiento de la discusión de la justicia social. Cuando Sen (1998) aborda el asunto de los funcionamientos, su perspectiva no se agota solamente en aquellos que se relacionan con la vida productiva y con ello marca diferencias de su postura con respecto a la teoría del capital humano. Las capacidades se atrofian por las condiciones de vida de los empobrecidos e incluso Sen (1998) reafirma el poder de la educación y del aprendizaje para el mejoramiento de las capacidades: las diferencias sociales no devienen de naturalezas distintas sino de procesos culturales diferenciadores.

Finalmente, sigue diciendo Sen, es importante recalcar también el papel instrumental de la expansión de la capacidad para generar el cambio social e ir, también, más allá del cambio económico. La capacidad es un instrumento más que la perspectiva del capital humano, sino también del desarrollo social, en uno ámbito de transformación que implica: su relación directa con el bienestar y la libertad de las personas; su función indirecta a través de 
su influencia en la producción económica; su función indirecta a través de su influencia en el cambio social.

La visión de Sen contiene otra vertiente relacionada con pobreza: su vínculo directo con el problema de la ciudadanía y, particularmente, el de ciudadanía social en su vínculo con la pobreza, que abre la puerta para el ineludible tema de la relación de la precariedad con la esfera del poder público y privado y con asuntos como la democracia. Los valores democráticos no son patrimonio de ninguna cultura en particular; se encuentran presentes en distintas experiencias en la historia y contextos: la libertad personal, la igualdad en la libertad, la tolerancia y la igualdad en la tolerancia. La política es parte de un enfoque integrado y global de desarrollo cuyo supuesto de partida es que no hay desarrollo sin compromiso político participativo y sin potenciar la capacidad de los actores sociales generando el malestar local a lo global (Stiglitz, 2002).

La inversión más fecunda que se puede hacer contra los riesgos, entonces, es en el aumento de las capacidades por medio de la salud, alimentación y en general de la calidad de vida pues lleva a mejorar las aptitudes de elección de cada uno de sus miembros. La atrofia de capacidades es producto de la situación de pobreza $^{* *} \mathrm{y}$ ésta, a su vez, refuerza las desigualdades sociales, los desniveles de participación democrática, entre otros lineamientos. La pobreza socioeconómica, la que produce precariedad en la alimentación, salud, vivienda, ingreso, agua, corriente eléctrica,

\footnotetext{
** Los dos ángulos sobre la pobreza presentados en este apartado, la de Sen y la que ejemplifica Boltvinik, no tienen alguna contradicción de fondo sino que miran la pobreza desde planos distintos, pero complementarios. La primera supone la segunda, pero la lleva a círculos más amplios y complejos.
}

seguridad social, bienes del hogar y educación, nos coloca, de forma clara, frente a la estructura social que produce un cierto tipo de crecimiento, concentración del ingreso, desigualdad regional e inestabilidad en el empleo.

La pobreza de capacidades, sin estar en contra de los fundamentos de la visión histórica-estructural, hace un análisis más fino de las consecuencias de la pobreza, la individualiza -por tanto hace emerger elementos visibles que pueden ser atacados mediante una política social efectiva- y evita que se caiga en una visión simplista de comprender la carencia de bienes sin considerar el impacto que tiene en las condiciones y posibilidades de los grupos empobrecidos para transformar el orden de cosas que no los beneficia.

Para resumir, se puede señalar que la pobreza no se origina de la ausencia de capacidades individuales o grupales sino tiene causas estructurales, pero ser pobre se constituye de la disminución de capacidades individuales, grupales y colectivas. Sobre la relación entre democracia y pobreza, Pérez Baltodano (1997: 55) afirma que "las estrategias y políticas para el desarrollo social juegan un papel crucial en un continente caracterizado por la pobreza, la marginalidad y la desigualdad social. Sin estrategias políticas y sociales capaces de responder a las necesidades más urgentes de la población de AL, los experimentos democráticos actuales tienden a convertirse en rituales políticos sin sentido ni significación social". El entendimiento de la pobreza como obstáculo y como precariedad que determina un acceso diferenciado a los recursos y a las capacidades mina no solamente la información sobre los procesos relacionados con la democracia representativa sino con el conocimiento de lo diseño de mecanismos para operar la democracia, 
entendida en el sentido de la concepción de ciudadanía civil, política y social. El conocimiento de las políticas sociales se relaciona a las muchas informaciones sobre las instituciones e de los actores sociales (Galiani, 2006).

La relación entre pobreza y democracia constituye problemas relacionados con la ciudadanía social y la desigualdad como fenómenos concurrentes en sociedades donde se ha avanzado en democracia, "son realmente preocupantes y constituyen el principal desafío de las democracias latinoamericanas, porque además, los grupos más excluidos del ejercicio pleno de la ciudadanía social son los que sufren carencias en otras dimensiones de la ciudadanía (...) estos fenómenos no permiten que los individuos se expresen como ciudadanos con plenos derechos" (PNUD, 2004: 26). Aun cuando uno de los propósitos de la política social es la definición de su papel ante la pobreza, tales fines no se agotan en el afán de compensar lo que la economía destruye, razón por que se demarca el debate sobre la ciudadanía. En la realidad actual, conforme Valencia y Geandreau (2000) la política social tiene como propósito básico restituir el tejido social, provocar situaciones dirigidas a disminuir la desigualdad, la inequidad y la exclusión social y restituir las capacidades de grupos y personas, o en lo mas combatir la inseguridad social y ambiental.

\section{La política social en el marco de la construcción de ciudadanía.}

La investigación sobre el bienestar desde diferentes argumentos y comprensión de la pobreza, en su vínculo con las capacidades políticas y sociales precisa profundizar el papel que juegan los actores y las instituciones en la hechura de políti- cas sociales. Desde la perspectiva de la ciudadanía se hace apuntes sobre los enlaces con derechos y la política social. En otros términos, las lecciones derivadas de la experiencia, más allá del desarrollo económico, nos enseñan que la expansión de la ciudadanía requiere un Estado de bienestar (Draibe y Riesco, 2006).

Para Pérez Baldotano (1997), en América Latina la política social tiene un alcance limitado como instrumento para combatir la exclusión y la promoción de la ciudadanía debido a que los estados de la región gozan un alto grado de autonomía con respecto a la sociedad civil y un alto grado de dependencia de la economía mundial $^{\dagger \dagger}$. En la gran mayoría de Latinoamérica se generaron condiciones para el desarrollo de dos tipos de políticas sociales: 1) la que genera una ciudadanía estatal, fruto del esquema corporativo, con un esquema de participación acotado y condicionado $y, 2$ ) la que se formula e instrumenta lejos de la participación ciudadana.

De estas reflexiones surge una aseveración que quizá sea la central para observar la relación entre ciudadanía y política social: "Este tipo de ciudadanía no se deriva, como en el caso europeo del desarrollo de la capacidad de la sociedad para condicionar el funcionamiento del Estado sino de la capacidad desarrollada por grupos y sectores de la sociedad para participar en el diseño y la formulación de decisiones y políticas públicas dentro del ámbito del Estado (...)". (Pérez Baltodano, 1997: 43). Con efecto, la ciudadanía posi-

\footnotetext{
$\dagger$ Esta situación contrasta con la característica fundamental de los estados europeos que, durante los últimos trescientos años, desarrollaron un alto grado de soberanía externa y un alto grado de dependencia doméstica. Esta combinación les permitió el desarrollo de una capacidad política que domesticó las economías nacionales para extraer y redistribuir recursos destinados al desarrollo social.
} 
ble se convierte en una reivindicación de una particular relación con el Estado nacional más que como un requerimiento de ordenamiento de ciudadanos frente el Estado.

Aunque esta afirmación no podría sostenerse en términos absolutos pues parte de las conquistas ciudadanas, en particular las obreras, las campesinas y las indígenas, son verdaderas reivindicaciones frente al Estado, se puede afirmar la existencia de ciertos rasgos marcados de una ciudadanía artificial promovida desde arriba y desde afuera por los estados latinoamericanos, misma que determina y explica en gran medida la noción de política social como alternativa excluyente de la lucha ciudadana, en tanto que ..."al lado de una élite privilegiada existe una gran masa de simples ciudadanos, la de los que están teóricamente sujetos a los rigores de la ley, pero que en la práctica dependen de la buena o mala voluntad de sus representantes" $(\mathrm{Mu}-$ rilo de Carvalho, 1995: 156), una ciudadanía no frente al Estado sino dependiente estructural del Estado, sujeta a la compasión pública.

La discusión sobre la ciudadanía se ha revitalizado, después de que se le daba por muerta en el ámbito o bajo el estructuralismo en las Ciencias Sociales de los 70, se regreso al vigor de compreender que la estabilidad de la democracia moderna no dependen solamente de la justicia de su estructura básica sino de las cualidades y actitudes de sus ciudadanos. Las políticas sociales emergen con el objetivo de introducir la garantía de los derechos sociales elementares para mitigar los efectos de las desigualdades, la inserción en el mercado laboral y el consumo de amplios sectores de la población. Existe un complemento entre la aceptación pasiva de derechos como atributo ciudadano (el derecho a tener derechos) y el ejercicio activo de las responsabilidades y virtudes ciudadanas. El aseguramiento de la integración de los pobres debe ir más allá de los derechos, focalizándose en su responsabilidad ${ }^{\$+}$ de ganarse la vida.

Si el Estado de bienestar ha causado una dependencia insana con respecto a la intervención estatal, lo conducente, según la derecha, es introducir las leyes del mercado en la vida de las personas y funcionar con el principio básico del workfare, es decir, la actividad laboral como contrapartida de los beneficios aportados por las políticas sociales. Medidas como el libre comercio, la desregulación, la disminución de impuestos, el debilitamiento de sindicatos y el recorte al seguro de desempleo se dirigen a promover la acción de hombres individuales, libres, con el propósito de enseñarles las virtudes de la iniciativa, la confianza en sí mismos y la autosuficiencia (Mulgan, apud Kymlika, 1997). La derecha confirma el papel absoluto del mercado en contra del resto de las fuentes de bienestar o defensores de focalizar los ingresos $y$ menos transferencia universal de ingresos para una equidad social (Stein, 2008).

Este discurso no representa sólo la expresión una postura distinta a lo que es ser ciudadano sino más bien atenta contra un principio de ciudadanía que la interpreta como un estatus independiente respecto del nivel económico: se tienen, formalmente, derechos ciudadanos, más allá del lugar que se ocupe en la economía. La postura

\footnotetext{
¥¥ La reestructuración económica, producto de la crisis de los modelos fordistas y en el contexto del consenso de Washington, realza el debate sobre la responsabilidad individual de abrirse un futuro de bienestar. E sentido contrario también existe un movimiento para estabelecer un consenso sobre lãs políticas sociales de gobiernos progresistas guiada por las inovaciones substantivas en la promoción de la ciudadania universal (Teixeira, 2009).
} 
critica ha venido ganando una claridad que su estatus actual aún se plantea como reto pues si bien es cierto que rechaza los principios emanados del Consenso de Washington, donde al parecer el único camino plausible es mercantilizar las relaciones sociales, le ha costado trabajo asumir la parte de la promoción que de verdad acerque a grupos y personas al ejercicio ciudadano como una real escuela de virtudes cívicas. En la línea de la promoción de complementar los mecanismos de respuesta institucional, Kymlika sostiene:

Las múltiples maneras en que las políticas públicas dependen de decisiones responsables a nivel de los estilos de vida personales: el Estado será incapaz de proveer cuidados sanitarios si los ciudadanos no actúan responsablemente hacia su propia salud; el Estado puede tornarse incapaz de satisfacer las necesidades de niños, ancianos y discapacitados si los ciudadanos no aceptan su cuota de responsabilidad en la atención de sus propios parientes (...) los intentos de crear una sociedad más justa tropezarán si los ciudadanos exhiben una intolerancia crónica hacia la diferencia o si carecen de lo que Rawls llama sentido de la justicia... lo que el Estado necesita de la ciudadanía no se puede obtener mediante la coerción sino solamente por medio de la cooperación y el autocontrol en el ejercicio del poder privado (Kymlika, 1997: 14).
A diferencia de las corrientes residuales, que piensan en el mercado como el principal factor de aprendizaje de las necesarias virtudes de un ciudadano propio del mundo moderno, existen otras respuestas que contemplan otros espacios de intervención tales como: el ejercicio de la democracia participativa (otorgar más poder al ciudadano), la construcción del republicanismo cívico (valor intrínseco de la vida política) y la participación en las organizaciones de la sociedad civil. La ciudadanía es un proceso que se construye con el elemento dinámico del compromiso con el entorno político.

Por su parte, Giovanna Procacci (1999) plantea que el concepto inicial de ciudadanía ha evolucionado desde un planteamiento formal-jurídico de pertenencia como miembro con derechos plenos a una sociedad y las formas constitucionales de ese derecho hacia una noción menos rígida. Todo ello conduce a la idea de que la ciudadanía no es simplemente un estatus legal definido por un conjunto de derechos y responsabilidades sino una identidad, la expresión de pertenencia a una comunidad política (Kymlika, 1997: 25). De manera complementaria Chantal Mouffe (1998; 2005), en la misma línea, sostiene que ser ciudadano obliga a una serie de lealtades múltiples con muchas comunidades diferentes y que éste no es un receptor pasivo de derechos en ninguna de ellas, ya que la lealtad contiene un conjunto de reglas y de prácticas orientadas a la construcción del juego de la ciudadanía pluralista.

Cuando el énfasis se pone en el multiculturalismo se abandona los principios universalistas de la ciudadanía social y el problema fundamental de la igualdad, así como la dimensión social de la ciudadanía parece obsoleta. En coincidencia con Kymlika, también Procacci (1999), bien 
como Barba y Valencia (2000) sostiene que varios procesos contemporáneos abonan al debilitamiento de la ciudadanía social y los derechos sociales, entre ellos: la individualización, la comercialización de los servicios, la flexibilidad laboral, la contractualización y el humanitarismo, todas ellas promovidas como soluciones cuasi absolutas. El planteamiento del mercado, la privatización de los servicios sociales y la filosofía del "usuario paga" están por encima de los planteamientos universalistas de la ciudadanía social.

Las políticas sociales nacen ante el fracaso del individualismo (caritativo, económico y jurídico) e históricamente han batallado contra la desigualdad, en particular la pobreza, que es uno de los principales problemas que han impedido formalizar un estatus de ciudadano. Particularmente importante para el tema de la política social es lo que señala Procacci (1999: 2729) sobre ciudadanía social y bienestar, la medida en que el deseo de asegurar un mínimo de bienestar no sólo es necesario sino que exige una intervención en el libre funcionamiento del mercado, redistribuyendo riqueza en forma de servicios públicos. Los servicios de bienestar social son un elemento constitutivo indispensable de la ciudadanía social o con la capacidad de romper con la injusta relación entre riqueza y pobreza en América Latina (Salama, 1999) y con la histórica deuda social.

La ciudadanía restaura el principio de reciprocidad al margen de las normas que rigen en el mercado, en el que se regula mediante el cambio de dinero y servicios, y al margen de las relaciones familiares cuya naturaleza es la ayuda mutua. Y mucho más afuera del ámbito de la cari$\mathrm{dad}$, en donde no existe ninguna reciprocidad: esto exige que la sociedad haya reconocido que hay ciertos niveles de vida que son imprescindibles, independientemente del poder de negociación del individuo. Al formularse estos niveles en términos de derechos, las dependencias a las que se pretende dar solución se transforman en condiciones para la autonomía (Procacci, 1999: 29). En coincidencia con autores como Esping-Andersen, Procacci y también Narbondo (2006) en su perspectiva crítica optan por un modelo universalista de los derechos que significa una relación con el Estado más allá de estimaciones contractuales.

El proceso de profundización de las desigualdades sociales constituye una de los fundamentos para la institucionalización o estructuración de los sistemas de protección social en un Estado de derecho o de la negociación de las demandas de la sociedad (Esping-Andersen, 1991; Filgueira, 2007). Están en la base del mencionado proceso político las luchas y las aspiraciones sociales de la clase obrera, a su vez conectados en la consolidación de alianzas políticas y en la expansión de las clases medias urbanas.

En oposición a la comprensión del gasto público en los costes de bienestar que debería reducir o contener los transforman en la perspectiva de una inversión social, un proyecto del futuro de la nación y de la ciudadanía. Una inversión en el futuro para proteger los ciudadanos de los riesgos y para comprobar que siga como autores de su destino para afrontar los retos de las incertidumbres del mañana (EspingAndersen y Palier, 2009). De esta manera suena como una gran mudanza social y política en una sociedad en rápido desarrollo de las incertidumbres sociales y ambientales.

La construcción de la ciudadanía moderna se ha convertido en la declaración característica de la relación de nexo entre 
la libertad/igualdad, el universalis$\mathrm{mo} /$ pluralismo y la igualdad/diferencia. Pero, cuyas tensiones no más aún siguen siendo la marca y parte del debate contemporáneo. Sin embargo, hay aspectos específicos en las tendencias de las prácticas políticas de los cambios recientes en la ciudadanía: el avance del reconocimiento de la diferencia y una fuerte regresión en términos de equidad (Lavalle, 2003). Un reciente análisis de la realidad a que está sujeto la ciudadanía en las naciones de Latinoamérica puede observar las consecuencias a través de las consideraciones sobre los aspectos de un diseño tradicional de la ciudadanía, sobre las fuerzas sociales responsables del reciente movimiento de la desestabilización y o regresión, así como sobre las reacciones a la desestabilización con diferentes referencias teóricas y las correspondientes tensiones y soluciones políticas.

El concepto básico del universalismo básico sugiere las políticas sociales en virtud de una orientación innovadora de la protección social en América Latina: fortalecimiento de la ciudadanía, la igualdad y la equidad como valores indispensables, y el papel del Estado en garantizar las cuestiones básicas. La propuesta se basa en el discurso de la ciudadanía y la igualdad se define el papel de las estatales que limitan su responsabilidad a las garantías de los derechos sociales, algunas prestaciones de servicios públicos se universalizan y los demás se deponen a los sistemas privados.

Como consecuencia coexisten en tres niveles claramente diferenciados la población pobre objeto de programas focalizados y asistenciales; un piso cada vez menos sólido constituido de una frágil población integrada, un tercer piso de altos ingresos constituido por mercados seguros de salud, de jubilaciones y pensiones $\mathrm{y}$ educación. Para atender esta situación los autores señalan con mucha claridad algunos obstáculos y plantean como ejes de trabajo futuro las estrategias sectoriales, la viabilidad fiscal, política y de gestión y las necesarias traducciones y adaptaciones nacionales.

De cara a la investigación particular en los países latinoamericanos conviene considerar un par de notas que sostienen de la propuesta del universalismo básico, con el objetivo de profundizar en los diagnósticos, no tan a fundamentar la necesidad del cambio sino para generar elementos que permitan especificar las diferencias entre los países de la región y proporcione guías útiles para construir la viabilidad política, fiscal y de gestión para el universalismo básico.

\section{Consideraciones finales}

Nos parece importante retomar luego algunos puntos que asoma la análisis de las Políticas Sociales para vislumbrar los riesgos y vulnerabilidades de los países de la región, en especial su finalidad explicitada por la gestión pública y su aplicación práctica por las políticas de combate a la pobreza. Si bien que la interpretación en particular requiere algo empírico, metodológico y estadístico, es importante recordar que no carece de una perspectiva teórica clave que son las estructuras de las sociedades nacionales que predisponen a un cierto tipo de riesgos y vulnerabilidad, que tampoco puede desentenderse - pues es la otra cara de la moneda - de la estructura que produce privilegios en sociedades periféricas o en desarrollo.

El diseño, concepción y implementación de políticas sociales con un sesgo de la desmercantilización constituye un pertinente mecanismo para que los ciudadanos 
tienen un nivel tolerable de bienestar y mediante la celebración de las cuestiones sociales y ambientales, cierta independencia frente a la lógica de competitividad mercantil. La desmercantilización se refiere al grado en que los individuos pueden mantener un nivel de vida, incluso en las condiciones en que se apartan, independientemente de su voluntad y fuerza política, del mercado de trabajo. Como resultado, una característica innovadora del derecho social de la ciudadanía, hace respeto, según Sposati (2007) a la posibilidad de una orientación no mercantilista de las políticas sociales en una sociedad muy desigual. Las políticas sociales como indicado garantizan alguno bienestar a los individuos que se quedan al marchen en relación a los procesos de trabajo en una sociedad con el desempleo estructural. En esta visión si establece un proceso para ampliar la capacidad de los individuos para acceder a los recursos y oportunidades para tomar suyas decisiones cotidianas.

El diseño, concepción y implementación de políticas sociales con un sesgo de la desmercantilización constituye un pertinente mecanismo para que los ciudadanos tienen un nivel tolerable de bienestar y mediante la celebración de las cuestiones sociales y ambientales, cierta independencia frente a la lógica de competitividad mercantil. La desmercantilización se refiere al grado en que los individuos pueden mantener un nivel de vida, incluso en las condiciones en que se apartan, independientemente de su voluntad y fuerza política, del mercado de trabajo. Como resultado, una característica innovadora del derecho social de la ciudadanía, hace respeto, según Sposati (2007) a la posibilidad de una orientación no mercantilista de las políticas sociales en una sociedad muy des- igual. Las políticas sociales como indicado garantizan alguno bienestar a los individuos que se quedan al marchen en relación a los procesos de trabajo en una sociedad con el desempleo estructural. En esta visión si establece un proceso para ampliar la capacidad de los individuos para acceder a los recursos y oportunidades para tomar suyas decisiones cotidianas.

En la acción de los actores sociales y políticos no lo constan los fenómenos que por sí mismos son imponderables o insuperables, lo que despliega un vasto campo de posibilidades políticas y propuestas en el marco analítico del pensamiento social. Las diversas políticas de bienestar planeadas y empleadas a lo largo de las últimas dos décadas han incorporado algunas críticas relativas al papel que desempeñan los actores sociales, ahora tienen una perspectiva universal, ahora se les distinguen por el foco de tipo compensatorio. En ambos los casos se atestigua cómo en las diferentes estrategias nacionales de protección social a los empobrecidos se valora el papel de la acción desempeñado por las mujeres, lo que constituye un importante paso metodológico y una dirección política para llenar a la comprensión de un vacío cultural del funcionamiento de los diversos mecanismos de afrontamiento.

El enfoque de la comprensión penetrante de los mecanismos que forjan las políticas sociales incluye los fenómenos históricos en sí mismos dinámicos y cambiantes, debido a la coexistencia de los constreñimientos o las limitaciones macroeconómicas. Nuestra expectativa es asegurarnos de que en la interpretación de Políticas Sociales estamos en el carril de ideas que nos llevan a entender que la producción de la inequidad es abordada desde la acción política y social. 


\section{Bibliografía.}

Adelantado, José (2000). Coord. Cambios en el estado de bienestar. Icaria-UAB. España.

Adelantado, José (2005). Desigualdad, democracia y políticas sociales focalizadas. Universidad de Barcelona, España.

Aguirre, Rodolfo y Román, Ignacio (2002). México. Veinte años de política económica. ITESO, SIMORELOS, SAPRIN. CD, Guadalajara, México.

Arraigada, Irmã; Aranda, Verônica (Orgs). (2004) Cambio de las familias en el marco de las transformaciones globales: necesidad de políticas públicas eficaces. Santiago/Chile: CEPAL/ONU,.

Arteaga, Carlos y Solís, Silvia. (2001) La política social en la transición. UNAM y Plaza y Valdés. México.

Barba, Carlos (2006). ¿ Reducir la pobreza o construir ciudadanía para todos? América Latina: regímenes de bienestar en transición al iniciar el siglo XXI. Universidad de Guadalajara.

Barba, Carlos y Valencia Enrique. (2000) Modelos de política social mexicana y combate a la pobreza. Versión en CD.

CEPAL (2005). Panorama Social de América Latina 2005. CEPAL, ONU. Chile.

Dagnino, Evelina, Alberto Olvera, Aldo Pamfici (Coord.) (2006). La disputa por la construcción democrática en América Latina. Fondo de Cultura Económi$\mathrm{ca} / \mathrm{CIESAS} /$ Universidad Veracruzana. México.

Draibe, Sonia; Riesco, Manuel. (2006). Estado de Bienestar, desarrollo económico y ciudadanía: algunas lecciones de la literatura contemporánea. Mexico, DF, CEPAL,. (Serie estudios y perspectivas, $55)$.

Esping-Andersen, Gosta (2000). Fundamentos sociales de las economías post industriales. Ariel, Barcelona, España.

Esping-Andersen, Gosta, Palier, Bruno. (2009). Três lições sobre o Estadoprovidência. Lisboa: Campo da Comunicação.

Esping-Andersen, Gosta. (1991). As três economias políticas do welfare state. Lua Nova, n. 24, CEDEC, pp. 85-116.

Esping-Andersen, Gosta. (2007). Les Trois Mondes de l'État Providenc. Paris: PUF, 2. ed.,.

Filgueira, Fernando, Molina, Jorge P. C.G. y Federico Tobar. (2006). "Universalismo Básico. Una alternativa posible y necesaria para mejorar las condiciones de vida en América Latina". Documento de Trabajo I-57, (Washington D.C.: BID/INDES), disponible en http://www.ciesu.edu.uy

Filgueira, Fernando. (1997). "Tipos de welfare y reformas sociales en América Latina. Eficiencia, residualismo y ciudadanía estratificada". In: Social Science Research Council. Guadalajara, 1997.

Filgueira, Fernando. (2007). Cohesión, riesgo y arquitectura de protección social en América Latina. Santiago de Chile: CEPAL.

Fleury, Sônia. \& Molina Carlos G. (2002). Modelos de Proteccion Social. In: Diseno y gerencia de políticas y programas sociales. Instituto Interamericano para el Desarrollo Social (INDES). Disponible http://www.rau.edu.uy/fcs/dts/Politicass ociales/Fleury.pdf 
Franzoni, Juliana M (2007). Regímenes Del Bienestar en America Latina Madri, Fundacion Carolina.

Franzoni, Juliana Martínez (2008) Domesticar la incertidumbre en América Latina. Mercado laboral, política social y familias. Instituto de Investigaciones Sociales. Universidad de Costa Rica. 2008.

Galiani, Sebastián (2006). Políticas sociales: instituciones, información y conocimiento. División de Desarrollo Social. CEPAL. Chile.

Gallardo, Rigoberto y Osorio, Joaquín (coord).(1998-1). Los rostros de la pobreza. El debate. Tomo I . SEUIA-ITESO. México.

Kymlicka ,W y Norman, W. (1997) El retorno del ciudadano. Una revisión de la producción reciente de la teoría de la ciudadanía. La Política. Revista de estudios sobre el Estado y la sociedad. Barcelona, $\mathrm{n}^{\mathrm{o}} 3$, pp. 5-39.

Lavalle, Adrián Gurza. Cidadania, igualdade e diferença. Lua Nova, n.59, Cedec, São Paulo, 2003, p.7594.

Lechner, Norbert (2002). Las sombras del mañana. Santiago de Chile, Lom.

Manow, Philip. (2007). As vantagens institucionais comparativas dos regimes de Estado de bem-estar social e as novas coalizões na sua reforma. In: Delgado, M.; Porto, Lorena. (Org.) O Estado de Bem-Estar Social no século XX. São Paulo: LTR, p.160-186.

Martínez, David (2008). Política Social y Pobreza en Guanajuato. Reconstrucción de una trayectoria útil para las entidades federativas. Colección Aportes. UIA León.
Molina, Carlos Gerardo (editor) (2006) Universalismo básico. Una nueva política social para América Latina. BID/Editorial Planeta. México.

Morlino, Leonardo (2005). Democracias y democratizaciones. México: CEPCOM.

Mouffe, Chantal (1999). El retorno a lo político. Paidos, Madrid.

Mouffe, Chantal. (2005). Por um modelo agonístico de democracia. Rev. Sociologia Politica, no.25, p.11-23.

Murilo de Carvalho, J (1995). Desenvolvimiento de la ciudadanía en Brasil. FCE, México.

Narbondo, Pedro. (2006). Critical reflections about basic universalism. Revista Uruguaya de Ciencia Política, Montevideo, vol.2, n.15, p.151-172.

Pereira, Potyara A. (2006). Necessidades Humanas: subsídios à critica dos míni-

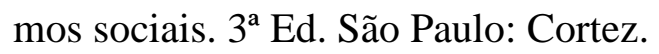

Pérez Baltodano, A. (1997). Globalización, ciudadanía y política social en AL. Nueva Sociedad, Caracas, Venezuela.

PNUD (2004). La democracia en América Latina. Hacia una democracia de ciudadanas y ciudadanos. Perú.

Procacci, Giovanna (1999) "Ciudadanos pobres. La ciudadanía social y la crisis de los estados de bienestar", en García, S. Y S. Lukes: Ciudadanía, justicia social y participación. Siglo XXI, Madrid.

Salama, Pierre (1999) Riqueza y pobreza en América Latina. FCE, U de G, México.

Sen Amartya (2000). Desarrollo y libertad. Editorial Planeta, México.

Sen, Amartya (1998). "Teorías del desarrollo en el siglo XXI" in Emerij, L. y 
Nuñez, Arco J. (comp.), El desarrollo económico y social en los umbrales del siglo XXI. BID Washington, EEUU.

Sposati, Aldaíza. (2007). Modelo de proteção social não contributiva: concepções fundantes. In: ENAP: Curso de Formação de Multiplicadores. Volume I. Brasília, p. 2-31.

Stein, Rosa Helena. (2008). Configuração recente dos programas de transferência de renda na América Latina: focalização e condicionalidade, in BOSCHETTI, I. et al. (orgs) Política Social no Capitalismo. Tendências contemporâneas. São Paulo: Cortez.

Stiglitz, Joseph (2002). El malestar de la globalización. Taurus, Madrid, España.

Teixeira, Zuleide Araújo. (2009). Consenso progresista desde el Sur, in Quiroga, Y.; Canzani, A. y Ensignia, J. (org). Consenso progresista: Las políticas sociales de los gobiernos progresistas del Cono Sur. Equador http://library.fes.de/pdffiles/bueros/chile/06402.pdf

Valencia, Enrique y Geandreau, M.(coord) (2000). Los dilemas de la política social. SEUIA-ITESO, U. de G., México.

Zimmermann, Clóvis R.; Silva, Marina C. (2009). O princípio da desmercantilização nas políticas sociais Cadernos CRH, vol.22, no.56, Salvador, p. 345-358. 